American Journal of Applied Sciences 7 (10): 1364-1371, 2010

ISSN 1546-9239

(C) 2010 Science Publications

\title{
Transient in-Cylinder Gas Flow Characteristics of Single Cylinder Port Injection Hydrogen Fueled Engine
}

\author{
${ }^{1,2}$ M.M. Rahman, ${ }^{1}$ Khalaf I. Hamada, ${ }^{1}$ M.M. Noor, ${ }^{1}$ Rosli A. Bakar, \\ ${ }^{1}$ K. Kadirgama and ${ }^{3}$ M.A. Maleque \\ ${ }^{1}$ Department of Mechanical Engineering, \\ ${ }^{2}$ Automotive Excellence Center, Faculty of Mechanical Engineering, \\ University Malaysia Pahang, 26600 Pekan, Kuantan, Pahang, Malaysia \\ ${ }^{3}$ Department of Manufacturing and Material, Engineering Faculty of Engineering, \\ International Islamic University Malaysia, Gombak, Selangor, Malaysia
}

\begin{abstract}
Problem statement: The variation of the in-cylinder gas flow characteristics for single cylinder port injection hydrogen fueled internal combustion engine was investigated through transient state simulation. Approach: One dimensional gas dynamics was described the flow and heat transfer in the components of the engine model. Special attention is paid to selection and correction of heat transfer correlation which describe of in-cylinder heat transfer to coincide with the practical observations. The engine model was simulated with variable engine speed and Air Fuel Ratio (AFR). Engine speed varied from 2000-5000 rpm with increment equal to $1000 \mathrm{rpm}$, while AFR changed from stoichiometric to lean limit. Results: The acquired results showed that the maximum in-cylinder temperature and pressure obtained of $2753 \mathrm{~K}$ and 49.62 bar at $24^{\circ} \mathrm{CA}$ ATDC and $13^{\circ} \mathrm{CA}$ ATDC for $\mathrm{AFR}=34.33$ respectively, while the minimum in-cylinder temperature and pressure obtained of $1366 \mathrm{~K}$ and 29.14 bar at $18 \mathrm{deg}$ CA of ATDC and $8 \mathrm{deg}$ CA of ATDC for AFR = 171.65 respectively. The obtained results show that AFR has a crucial effect on characteristics variation during the power cycle whilst engine speed has minor effects. Conclusion: These results utilized for study the combustion process, fuel consumption, emission production and engine performance.
\end{abstract}

Key words: Hydrogen fuel, specific heat ratio, port injection, engine speed, air fuel ratio, transient

\section{INTRODUCTION}

Hydrogen, as alternative fuel, has unique properties give it significant advantage over other types of fuel. Hydrogen can be used as a clean alternative to petroleum fuels and its use as a vehicle fuel is promising in the effects to establish environmentally friendly mobility systems. So far, extensive studies were investigated hydrogen fueled internal combustion engines (White et al., 2006; Kahraman et al., 2007; Rahman et al., 2009a; 2009b). With increasing concern about the energy shortage and environmental protection, research on improving engine fuel economy, hydrogen fueled engine is being developed into a hydrogen fueled engine with different type of fuel supply method (Kahraman et al., 2007; Rahman et al., 2009a; 2009b; Kim et al., 2005; Bakar et al., 2009). Residue and pollution by emissions were produced by the growing number of vehicles on the road day by day increases. Hydrogen is particularly suitable for fueling internal combustion engines (Yusaf et al., 2005). The flow field identification inside a cylinder of the internal combustion engines during the intake, compression, expansion and exhaust strokes are an important stage for the comprehension of physical phenomenon which occurs in the motor cycle. The movement of the inlet air-fuel mixture in the cylinder has a great influence in to the performance of the engine. Developments in engine simulation technology have made the virtual engine model a realistic suggestion (Li et al., 2000). Now-a-day the usage of Computational Fluid Dynamics (CFD) codes are used to simulation the engine performance and visualize the flow characteristics (Khalighi et al., 1994). Using CFD codes for engine improvement programs have saved significant time and cost for the design and development of combustion engine system (Shojaeefard and Noorpoor, 2008). Computational modeling and analysis of the gas flow in-cylinder is a major part of successful combustion, emission

Corresponding Author: M.M. Rahman, Automotive Excellence Center, Faculty of Mechanical Engineering,

University Malaysia Pahang, 26600 Pekan, Kuantan, Malaysia Tel: +609-4242246/Fax: +609-4242202 
production and engine performance simulation. Realization of the in-cylinder gas flow characteristics for the internal combustion engine is very substantial for advanced understanding and further optimization of the engine. The in-cylinder gas flow field characteristics have major influence on combustion process, fuel consumption, emission production and engine performance. The main goal for the present study is to investigate the variation of the in-cylinder gas flow characteristics for the hydrogen fueled internal combustion engine by utilizing CFD analysis. The effects of engine speed and AFR on in-cylinder gas flow field characteristics are also revealed.

\section{MATERIALS AND METHODS}

Engine model: A single cylinder, four stroke spark ignition port injection hydrogen fuel was developed in this study. GT-Suite was utilizing the development of engine model. The injection of hydrogen was located in the midway of the intake port. The computational model of the single cylinder four stroke port injection hydrogen fueled engine are shown in Fig. 1. The engine specifications are listed in Table 1. It is important to indicate that the intake and exhaust ports of the engine cylinder are modeled geometrically with pipes. The air enters through a bell-mouth orifice to the pipe. The discharge coefficients of the bell-mouth orifice were set to 1 to ensure the smooth transition as in the real engine. The pipe of bell-mouth orifice with $0.07 \mathrm{~m}$ of diameter and $0.1 \mathrm{~m}$ of length are used in this model. The pipe connects in the intake to air cleaner with 0.16 $\mathrm{m}$ of diameter and $0.25 \mathrm{~m}$ of length. The air cleaner pipe identical to the bell-mouth orifice connects to the manifold. A log style manifold was developed from a series of pipes and flow-splits. The total volume for each flow-split was $256 \mathrm{~cm}^{3}$. The flow-splits compose from an intake and two discharges. The intake draws air from the preceding flow-split. One discharge supplies air to adjacent intake runner and other supplies air to the next flow-split. The last discharge pipe was closed with a cup. The flow-splits are connected with each other through pipes with $0.09 \mathrm{~m}$ diameter and $0.92 \mathrm{~m}$ length. The junctions between the flow-splits and the intake runners were modeled with bell-mouth orifices.

The discharge coefficients were also set to 1 to assure smooth transition, because in most manifolds the transition from the manifold to the runners is very smooth. The intake runners for the four cylinders were modeled as four identical pipes with $0.04 \mathrm{~m}$ diameter and $0.1 \mathrm{~m}$ length. Finally the intake runners were linked to the intake ports which were modeled as pipes with
$0.04 \mathrm{~m}$ diameter and 0.08 length. The temperature of the piston is higher than the cylinder head and cylinder block wall temperature. Heat transfer multiplier is used to take into account for bends, additional surface area and turbulence caused by the valve and stem. The pressure losses in these ports are included in the discharge coefficients calculated for the valves. No additional pressure losses due to wall roughness were used.

The exhaust runners were modeled as rounded pipes with $0.03 \mathrm{~m}$ inlet diameter and 800 bending angle for runners 1 and 4 and 400 bending angle of runners 2 and 3. Runners 1 and 4 and runners 2 and 3 are connected before enter in a flow-split with $169.646 \mathrm{~cm}^{3}$ volume. Conservation of momentum is solved in 3dimentional flow-splits even though the flow in GTPower is otherwise based on a one-dimensional version of the Navier-Stokes equation. Finally a pipe with 0.06 $\mathrm{m}$ diameter and $0.15 \mathrm{~m}$ length connects the last flowsplit to the environment. Exhaust system walls temperature was calculated using a model embodied in each pipe and flow-split.

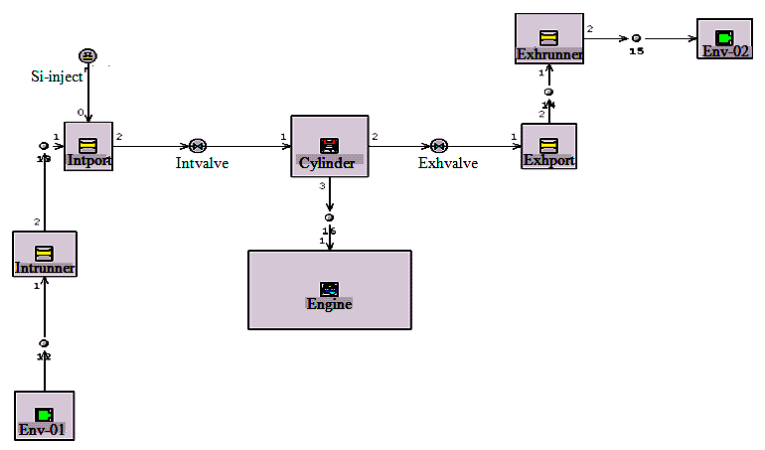

Fig. 1: Model of single cylinder, four stroke port injection hydrogen fueled engine

Table1: Engine specification

\begin{tabular}{lrl}
\hline Engine parameter & Value & Unit \\
\hline Bore & 100.0 & $\mathrm{~mm}$ \\
Stroke & 100.0 & $\mathrm{~mm}$ \\
Total displacement & 3142.0 & $\left(\mathrm{~cm}^{3}\right)$ \\
Connecting rod length & 220.0 & $\mathrm{~mm}$ \\
Compression ratio & 9.5 & \\
Intake valve close, IVC & -96.0 & ${ }^{\circ} \mathrm{CA}$ \\
Exhaust valve open, EVO & 125.0 & ${ }^{\circ} \mathrm{CA}$ \\
Inlet valve open, IVO & 351.0 & ${ }^{\circ} \mathrm{CA}$ \\
Exhaust valve close, EVC & 398.0 & ${ }^{\circ} \mathrm{CA}$ \\
Heat transfer coefficient & 15.0 & $\mathrm{~W} \mathrm{~m}{ }^{-2} \mathrm{~K}$ \\
Layer thickness & 3.0 & $\mathrm{~mm}$ \\
Piston & 590.0 & $\mathrm{~K}$ \\
Cylinder head & 550.0 & $\mathrm{~K}$ \\
Radiative temperature & 320.0 & $\mathrm{~K}$ \\
\hline
\end{tabular}


A simulation of the wall heat transfer is an imperative condition for the accurate analysis of the working process of ICE. The engine model is to estimate the engine heat transfer using Woschni (1967) correlation. The original values of the constant in the correlation were multiplied by factor equal to 1.8 , resulting in a better match with the experimental data (Aceves and Smith, 1996). The authors were found during the analysis that the heat transfer correlation under predicts heat transfer loss.

Heat transfer modeling equations: One dimensional gas dynamics to represent the flow and heat transfer in the components of the engine model. Engine performance can be studied by analyzing the mass, momentum and energy flows between individual engine components and the heat and work transfers within each component. To complete the simulation model other additional formulas beside of the main governing equations are used for calculations of the pressure loss coefficient, friction coefficient, heat transfer and heat release rate.

The pressure loss coefficient is defined as in (1):

$\mathrm{C}_{\mathrm{pl}}=\frac{\mathrm{p}_{2}-\mathrm{p}_{1}}{\frac{1}{2} \rho \mathrm{u}_{1}^{2}}$

where, $\mathrm{p}_{1}$ and $\mathrm{p}_{2}$ are the inlet and outlet pressure respectively, $\rho$ the density and $u_{1}$ the inlet velocity.

The friction coefficient can be expressed for smooth and rough walls as in (2) and (3) respectively:

$$
\begin{aligned}
& C_{f}=\frac{16}{\operatorname{Re}_{D}} \quad \operatorname{Re}_{D}<2000 ; \operatorname{Re}_{D}=\frac{v D}{v} \\
& C_{f}=\frac{0.08}{\operatorname{Re}_{D}^{0.25}} \quad \operatorname{Re}_{D}>4000 \\
& C_{f(\text { rough })}=\frac{0.25}{\left(2 \log _{10}\left(\frac{D}{2 h}\right)+1.74\right)^{2}}
\end{aligned}
$$

where, $\mathrm{Re}_{\mathrm{D}}, \mathrm{D}$ and $\mathrm{h}$ are Reynolds number, pipe diameter and roughness height respectively.

The heat transfer from the internal fluids to the pipe and flow split walls is dependent on the heat transfer coefficient, the predicted fluid temperature and the internal wall temperature. The heat transfer coefficient is calculated every time step and it is a function of fluid velocity, thermo-physical properties and wall surface roughness. The internal wall temperature is defined as in (4): $\mathrm{h}_{\mathrm{g}}=\frac{1}{2} \mathrm{C}_{\mathrm{f}} \rho \mathrm{U}_{\text {eff }} \mathrm{C}_{\mathrm{p}} \operatorname{Pr}^{-\frac{2}{3}}$

where, $\mathrm{U}_{\text {eff }}, \mathrm{C}_{\mathrm{p}}$ and $\mathrm{Pr}$ are the effective speed outside boundary layer, specific heat and Prandtl number respectively. The Prandtl number can be expresses as in (5):

$\operatorname{Pr}=\frac{v}{\alpha}$

where, $v$ and $\alpha$ are the kinematic viscosity and thermal diffusivity respectively.

The heat transfer coefficient depends on characteristic length, transport properties, pressure, temperature and characteristic velocity. There is a wealth of heat transfer correlations for describing heat transfer process inside combustion chamber such as Eichelberg (1939) equation Woschni (1967) equation and Annand (1963) equation. The in-cylinder heat transfer is calculated by a formula which closely emulates the classical Woschni correlation. The heat transfer coefficient can be expressed as in (6):

$$
\begin{aligned}
& \mathrm{h}=3.26 \mathrm{D}^{-0.2} \mathrm{P}^{0.8} \mathrm{~T}_{\mathrm{g}}^{-0.55} \mathrm{w}^{0.8} \\
& \mathrm{w}=2.28 \mathrm{C}_{\mathrm{m}}+0.00324 \frac{\left(\mathrm{P}-\mathrm{P}_{\mathrm{m}}\right) \mathrm{V}_{\mathrm{h}} \mathrm{T}_{\mathrm{r}}}{\mathrm{P}_{\mathrm{r}} \mathrm{V}_{\mathrm{r}}}
\end{aligned}
$$

where, $\mathrm{D}, \mathrm{P}, \mathrm{P}_{\mathrm{m}}, \mathrm{T}_{\mathrm{g}}, \mathrm{V}_{\mathrm{h}}, \mathrm{C}_{\mathrm{m}}, \mathrm{V}_{\mathrm{r}}$ and $\mathrm{r}$ are the bore diameter, pressure, motored pressure, gas temperature, volume, mean piston speed, swept volume and reference crank angle respectively.

The engine model for Aceves and Smith (1996) estimate engine heat transfer by using Woschni (1967) correlation. It was found during the analysis that the heat transfer correlation under predicts heat transfer loss. Therefore, for the present model the original values of the constant in the correlation were multiplied by factor equal to 1.8 , resulting in a better match with the experimental data according to (Aceves and Smith, 1996). The rate of heat release as a function of crank angle is obtained by differentiating the cumulative heat release Weibe function (Ferguson and Kirkpatrick, 2000):

$\frac{\mathrm{dQ}}{\mathrm{d} \theta}=\mathrm{Q}_{\mathrm{in}} \frac{\mathrm{dx}_{\mathrm{b}}}{\mathrm{d} \theta}=\mathrm{n} \times \mathrm{a} \frac{\mathrm{Q}_{\mathrm{in}}}{\theta_{\mathrm{d}}}\left(1-\mathrm{x}_{\mathrm{b}}\right)\left(\frac{\theta-\theta_{\mathrm{s}}}{\theta_{\mathrm{d}}}\right)^{\mathrm{n}+1}$

Where:

$\mathrm{Q}=$ Heat release

$\mathrm{Q}_{\text {in }}=$ Lower heating value 
Therefore, the mass fraction burned is known as a function of crank angle and the apparent heat release can be approximated. When the mass fraction burned is graphed against crank angle degrees, the curve can be described using a Wiebe function (Ferguson and Kirkpatrick, 2000):

$\mathrm{x}_{\mathrm{b}}(\theta)=1-\exp \left[-\mathrm{a}\left(\frac{\theta-\theta_{\mathrm{s}}}{\theta_{\mathrm{d}}}\right)^{\mathrm{n}}\right]$

In (8):

$\mathrm{x}_{\mathrm{b}}=$ The cumulative heat release fraction

$\theta=$ Crank angle degrees

$\theta_{\mathrm{s}}=$ Corresponding to the initialization of heat release

$\theta_{\mathrm{d}}=$ Corresponding to the duration of burn

The equation is also defined by two constants a and $\mathrm{n}$ where $\mathrm{n}$ : Weibe form factor, a: Weibe efficiency factor which have typical values of 3 and 5 respectively.

\section{RESULTS}

Transient gas flow and heat transfer simulations for the in-cylinder of four stroke port injection spark ignition hydrogen fueled engine model was run for two operation parameters namely air-fuel ratio AFR and engine speed. The air-fuel ratio AFR was varied from stoichiometric limit AFR $=34.33: 1$ based on mass where the equivalence ratio $(\varphi=1.0)$ to a very lean limit AFR $=171.65$ where $(\varphi=0.2)$ with change step for the equivalence ratio equal to 0.2 and engine speed varied from $2000-5000 \mathrm{rpm}$ with change step equal to $1000 \mathrm{rpm}$.

Model validation: The experimental results obtained from Lee et al. (1995) were used for purpose of validation in this study. Engine specifications of and present single cylinder port injection engine model are listed in Table 2. The similar engine model which described in Fig. 1 with specification listed in Table 2 was used for the purpose of validation. Engine speed and AFR were fixed at $1500 \mathrm{rpm}$ and $68.66(\varphi=0.5)$ respectively according to. The correlation of in-cylinder pressure of baseline model and experimental previous published results of are shown in Fig. 2. It can be seen that pressure are good agreement for compression and expansion strokes while large deviation was obtained for combustion period due to the delay in the combustion for experimental and difference in valve timing between the experimental and present model and some engine configuration conditions that is not mentioned in. However, considerable coincident between the present model and experimental results can be recognized in spite of the mentioned model differences.

Table 2: Specifications of the engines models

\begin{tabular}{llcl}
\hline Engine parameter & $\begin{array}{l}\text { Lee } \text { et al. } \\
(1995)\end{array}$ & Present model & Unit \\
\hline Bore & 85 & 85.0 & $\mathrm{~mm}$ \\
Stroke & 86 & 86.0 & $\mathrm{~mm}$ \\
TDC clearance height & NA* & 3.0 & $\mathrm{~mm}$ \\
Piston pin offset & NA & 1.0 & $\mathrm{~mm}$ \\
Connecting rod length & NA & 150.0 & $\mathrm{~mm}$ \\
Compression ratio & 8.5 & 8.5 & - \\
Inlet valve open $\left(^{\circ}\right)$ & 16 & 9.0 & $\mathrm{CA}$ (BTDC) \\
Exhaust valve open $\left(^{\circ}\right)$ & 52 & 55.0 & $\mathrm{CA}$ (BBDC) \\
Inlet valve close $\left(^{\circ}\right)$ & 54 & 84.0 & $\mathrm{CA}$ (ABDC) \\
Exhaust valve close $\left(^{\circ}\right)$ & 12 & 38.0 & $\mathrm{CA}$ (ATDC) \\
\hline
\end{tabular}

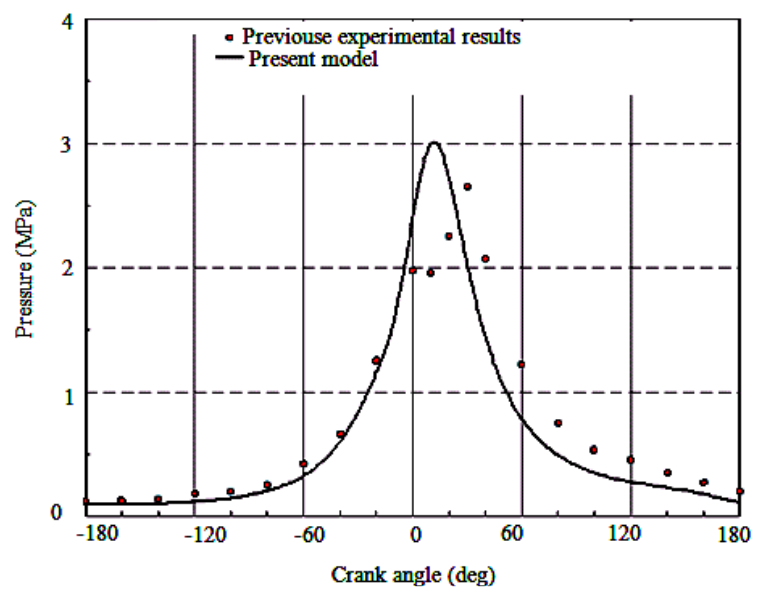

Fig. 2: Comparison between published experimental results Lee et al. (1995) and present model

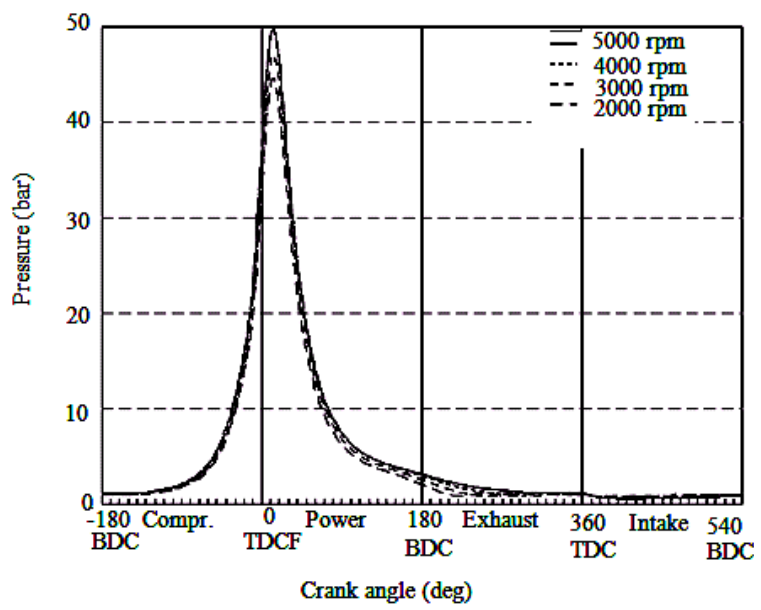

Fig. 3: Variation of in-cylinder pressure against crank angle 
Variation of In-cylinder pressure: Variation of incylinder pressure against crank angle with different engine speed is shown in Fig. 3. During compression stroke, the pressure increases continuously due to movement of the piston to TDC and proceed with the process of closing the inlet and exit valves. Beyond the end of compression stroke (TDC), the pressure increases rapidly until the peak pressure location as a result of combustion occurrence immediately after TDC. As a result to begin the expansion stroke after TDC, the pressure drop dramatically beyond the peak pressure location and continue with small gradient for other cycle strokes (exhaust and intake) because of starting the process of opening exit and inlet valves alternately. It can be seen that the pressure increases with increases of engine speed. The maximum pressures are obtained of 50 and 45 bar at 5000 and $2000 \mathrm{rpm}$ respectively. The difference is clearer at peak pressure location.

Effect of AFR on the variation of in-cylinder pressure against crank is also presented in Fig. 4. The same trends occurred for the variation of pressure with crank angle for the peak pressure values at TDC and beyond this point. The maximum pressure decreases as AFR increases. This result is agreed with observation of (Abd Alla, 2002; Verhelst and Sierens, 2007). The maximum pressure are obtained of 49.62 and 29.14 bar at AFR of 34.33 and 171.65 respectively due to the decrease amount of hydrogen in inlet charge to the cylinder.

Variation of In-cylinder Gas temperature: The variation of in-cylinder gas temperature against crank angle for different engine speed is shown in Fig. 5 .

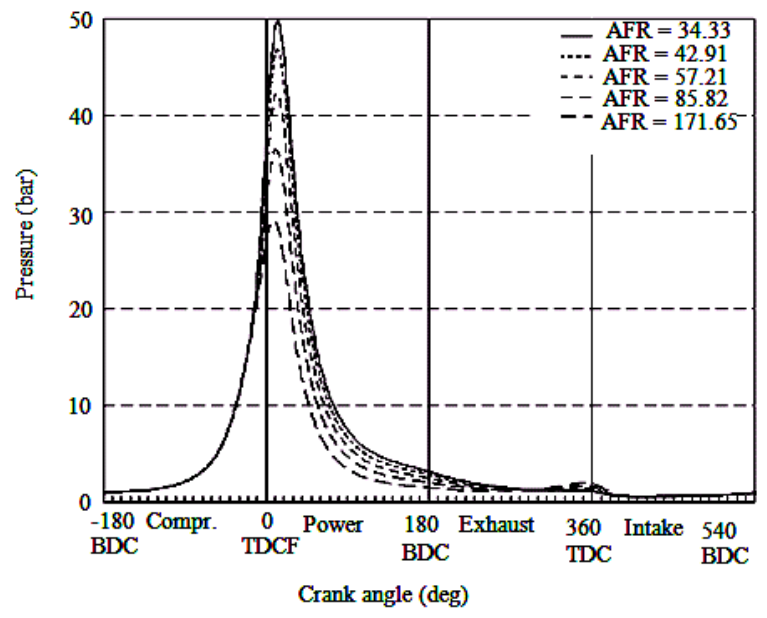

Fig. 4: Variation of in-cylinder gas pressure for different AFR
According to the equation of state for the ideal gas, temperature is a function of the pressure. Gas temperature variation inside the cylinder is identical pattern with the pressure profile. For the compression stroke the in-cylinder gas temperature increases continuously with coincident behavior for the incylinder pressure. Behind the end of compression stroke (TDC) the in-cylinder gas temperature increases rapidly untill the peak temperature location as a result of combustion occurrence after TDC. However the incylinder gas temperature is starting decrease during expansion stroke but have smaller gradient compare with in-cylinder pressure for the same period. The temperature drop is continuously for other cycle strokes (power and exhaust) with the same gradient for the exhaust stroke whilst rapidly gradient at the beginning of intake stroke due to opening of intake valve and thus a fresh cool charge enter to the cylinder. It can be seen that the maximum temperature obtained at higher engine speed; however, the difference is clearer after TDC during the combustion period.

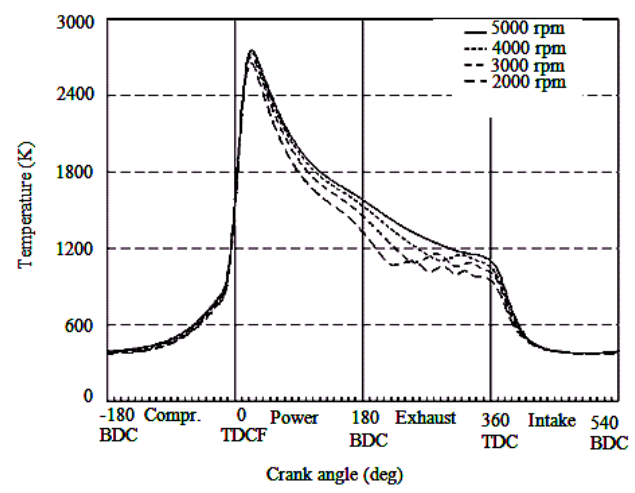

Fig. 5: Variation of in-cylinder gas temperature for different speed

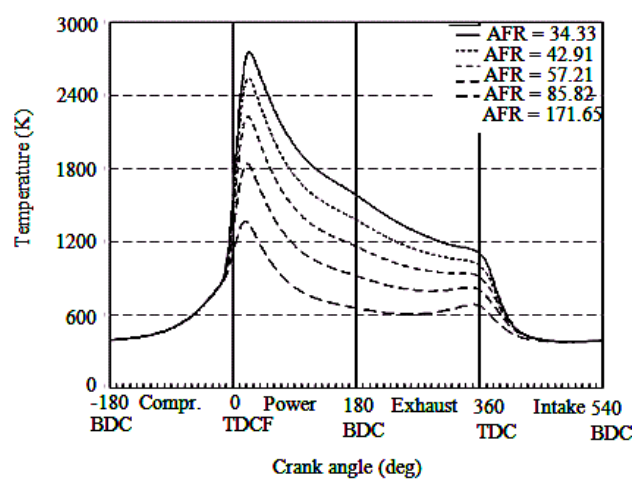

Fig. 6: Variation of in-cylinder gas temperature for different AFR 
Effect of AFR on the variation of in-cylinder gas temperature against the crank angle is shown in Fig. 6. It can be seen that AFR has more crucial effect on the incylinder temperature. This is due to the temperature dependency on the amount of fuel in the inlet charge to the cylinder. The maximum temperature for AFR = 34.33 is $2753 \mathrm{~K}$ at $24 \mathrm{deg}$ CA of ATDC whereas for $\mathrm{AFR}=171.65$ is $1366 \mathrm{~K}$ at $18 \mathrm{deg}$ CA of ATDC.

Peak temperature values are appears ATDC due to start combustion at TDC and continue the combustion process till finish all fuel inside the cylinder. Same observation is obtained by (Shudo et al., 2001) about general behavior for the temperature during compression and expansion strokes, which are just available for above mentioned strokes only.

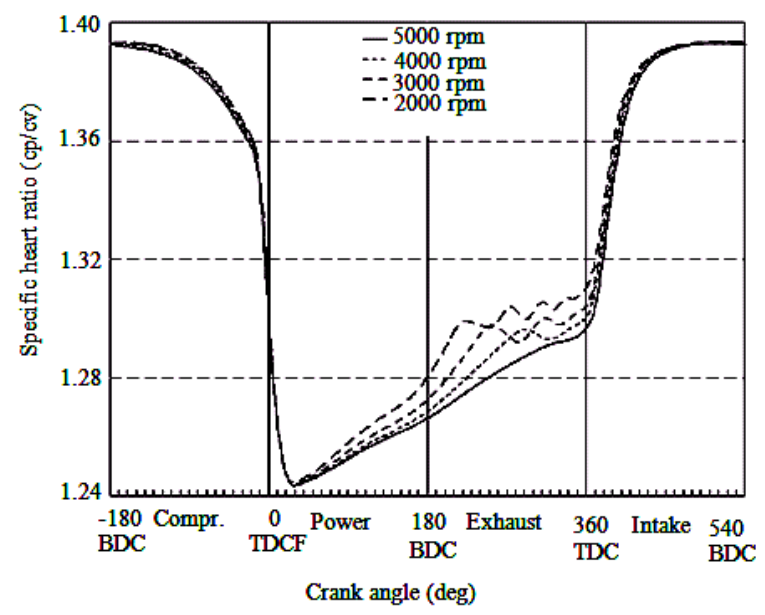

Fig. 7: Variation of in-cylinder gas specific heat ratio for different engine speed

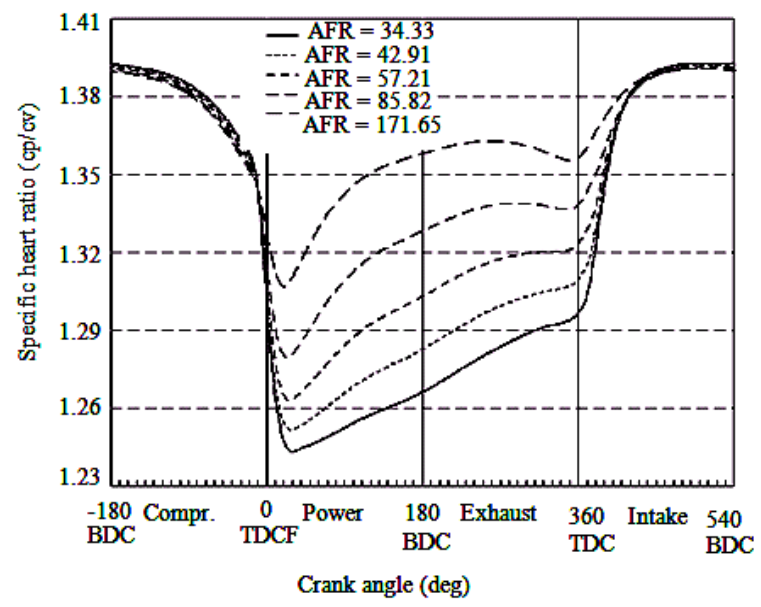

Fig. 8: Variation of in-cylinder gas specific heat ratio for different AFR
Effect of in-cylinder gas specific heat ratio: The analysis of heat release rate in the internal combustion engine requires the knowledge of the specific heat ratio for involved working medium. Variation of in-cylinder gas specific heat ratio against crank angle for different engine speed is shown in Fig. 7. Sharp variation in specific heat ratio value is occurred during the combustion period due to the change in the mixture composition. Effect of engine speed is negligible before combustion. While the difference is clearer after combustion and during power and exhaust stroke due to expansion occurrence and exhaust valve opening, this means giving greater freedom of movement of the gases for these strokes. So, for these two strokes, the gas specific heat ratio will show some dependence on the value of engine speed as one of parameters affecting on the driving force for the gas movement inside the cylinder.

Specific heat ratio depends mainly on engine fuel and mixture composition. Behavior of specific heat ratio for different AFR is exhibited in Fig. 8. The general trends of gas specific heat ratio have similar behavior for all AFR except for the values $(85.82,171.65)$, which have small difference during power and exhaust strokes. This is because of increasing the air amount per charge was entered to the cylinder. In addition, it can be seen that the variation of specific heat ratio decrease as AFR increase due to decrease the amount of hydrogen per charge enter to combustion chamber.

\section{DISCUSSION}

Through the previous section the effect of engine speed and AFR on the in-cylinder gas flow characteristics are clarified under transient condition in case of hydrogen fuel. The behavior of the transient in-cylinder gas flow characteristics found to be governed by the energy content and forced convection effects. Forced convection effect is related to engine speed variation, while the energy content effect is related to AFR variation. It can be seen that during compression stroke, the pressure increases continuously due to movement of the piston to TDC and proceed with the process of closing the inlet and exit valves. Beyond the end of compression stroke (TDC), the pressure increases rapidly until the peak pressure location as a result of combustion occurrence immediately after TDC. As a result to begin the expansion stroke after TDC, the pressure drop dramatically beyond the peak pressure location and continue with small gradient for other cycle strokes (exhaust and intake) because of starting the process of opening exit and inlet valves alternately. 
Gas temperature variation inside the cylinder is identical pattern with the pressure profile. For the compression stroke the in-cylinder gas temperature increases continuously with coincident behavior for the in-cylinder pressure. Behind the end of compression stroke (TDC) the in-cylinder gas temperature increases rapidly until the peak temperature location as a result of combustion occurrence after TDC. However the in-cylinder gas temperature is starting decrease during expansion stroke but have smaller gradient compare with incylinder pressure for the same period. The temperature drop is continuously for other cycle strokes (power and exhaust) with the same gradient for the exhaust stroke whilst rapidly gradient at the beginning of intake stroke due to opening of intake valve and thus a fresh cool charge enter to the cylinder. It can be seen that AFR has more crucial effect on the in-cylinder temperature. This is due to the temperature dependency on the amount of fuel in the inlet charge to the cylinder. Peak temperatures values are appear ATDC due to start combustion at TDC and continue the combustion process till finish all fuel inside the cylinder. Same observation is obtained by (Shudo et al., 2001) about general behavior for the temperature during compression and expansion strokes, which are just available for above mentioned strokes only.

Sharp variation in specific heat ratio value is occurred during the combustion period due to the change in the mixture composition. Effect of engine speed is negligible before combustion. While the difference is clearer after combustion and during power and exhaust stroke due to expansion occurrence and exhaust valve opening, this means giving greater freedom of movement of the gases for these strokes. So, for these two strokes, the gas specific heat ratio will show some dependence on the value of engine speed as one of parameters affecting on the driving force for the gas movement inside the cylinder. The general trends of gas specific heat ratio have similar behavior for all AFR except for the values (85.82, 171.65), which have small difference during power and exhaust strokes. This is because of increasing the air amount per charge was entered to the cylinder. In addition, it can be seen that the variation of specific heat ratio decrease as AFR increase due to decrease the amount of hydrogen per charge enter to combustion chamber.

\section{CONCLUSION}

One dimensional CFD model to predict the variation of transient in-cylinder gas flow characteristics was developed. In this study, it was emphasized to illustrate the effect of engine speed and AFR on in-cylinder gas pressure and temperature as direct impact on all engine performance parameters. The results have been achieved by using the instantaneous state simulations for better understanding of the in-cylinder characteristics variation in the hydrogen fueled internal combustion engine. The simulation results are employed to examine the effect of operation parameters (engine speed and AFR) on the variation of in-cylinder gas flow characteristics. This study can be extended with other subjects such as injection and heat release to obtain a complete model of the hydrogen fuelled internal combustion engine.

\section{ACKNOWLEDGMENT}

The researcher would like to thank University Malaysia Pahang for provides laboratory facilities and financial support under project no. RDU0903093.

\section{REFERENCES}

Abd Alla, G.H., 2002. Computer simulation of a four stroke spark ignition engine. Energy Conver. Manage., 43: 1043-1061. DOI: 10.1016/S01968904(01)00092-9

Aceves, S.M. and J.R. Smith, 1996. Lean-burn hydrogen spark-ignited engines: The mechanical equivalent to the fuel cell. Proceeding of the Society of Automotive Engineers International Congress and Exposition Detroit, Oct. 6-10, ASME, Michigan, pp: $1-23$.

http://www.osti.gov/bridge/product.biblio.jsp?osti_i $\mathrm{d}=402294$

Annand, W.J.D., 1993. Heat transfer in the cylinders of reciprocating internal combustion engines. Proc. Inst. Mech. Eng., 177: 973-996. DOI: 10.1243/PIME_PROC_1963_177_069_02

Bakar, R.A., M.K. Mohammed and M.M. Rahman, 2009. Numerical study on the performance characteristics of hydrogen fueled port injection internal combustion engine. Am. J. Eng. Applied Sci., 2 : $407-415 . \quad$ DOI: 10.3844/ajeassp.2009.407.415

Eichelberg, G., 1939. Some new investigations on old combustion engine problems. Engineering, 148: 547-550.

Ferguson, C.R. and A.T. Kirkpatrick, 2000. International Combustion Engines: Applied Thermosciences. 2nd Edn., Wiley, New York, ISBN: 10: 0471356174, pp: 384. 
Kahraman, E., S.C. Ozcanli and B. Ozerdem, 1007. An experimental study on performance and emission characteristics of a hydrogen fuelled spark ignition engine. Int. J. Hydrogen Energy, 32: 2066-2072. DOI: 10.1016/j.ijhydene.2006.08.023

Khalighi, B., D.C. Haworth and M.S. Hubler, 1994. Multidimensional port-and in-cylinder flow calculations and flow vision study in an internal combustion engine with different intake configurations. SAE. http://www.sae.org/technical/papers/941871

Kim, Y.Y., J.T. Lee and G.H. Choi, 2005. An investigation on the cause of cycle variation in direct injection hydrogen fueled engines. Int. J. Hydrogen Energy, 30: 69-76. DOI: 10.1016/j.ijhydene.2004.03.041

Lee, S.J., H.S. Yi and E.S. Kim, 1995. Combustion characteristics of intake port injection type hydrogen fueled engine. Int. J. Hydrogen Energy, 20: 317-322. DOI: 10.1016/0360-3199(94)00052-2

Li, G., S.M. Sapsford and R.E. Morgan, 2000. CFD simulation of a DI truck engine using VECTIS. SAE. http://www.sae.org/technical/papers/2000-012940

Rahman, M.M., M.K. Mohammed and R.A. Bakar, 2009a. Effect of air fuel ratio and injection timing on performance for four cylinder direct injection hydrogen engine. Eur. J. Sci. Res., 25: 214-225. http://www.eurojournals.com/ejsr_25_2_05.pdf

Rahman, M.M., M.K. Mohammed and R.A. Bakar, 2009b. Effects of air fuel ratio and engine speed on performance of hydrogen fueled port injection engine. J. Applied Sci., 9: 1128-1134. DOI: 10.3923/jas.2009.1128.1134
Shojaeefard, M.H. and A.R. Noorpoor, 2008. Flow simulation in engine cylinder with spring mesh. Am. J. Applied Sci., 5: 1336-1343. DOI: 10.3844/ajassp.2008.1336.1343

Shudo, T., S. Nabetani and Y. Nakajima, 2001. Analysis of the degree of constant volume and cooling loss in a spark ignition engine fuelled with hydrogen. Int. J. Engine Res., 2: 81-92. DOI: 10.1243/1468087011545361

Verhelst, S. and R. Sierens, 2007. A quasi-dimensional model for the power cycle of a hydrogen-fuelled ICE. Int. J. Hydrogen Energy, 32: 3545-3554. DOI: 10.1016/j.ijhydene.2007.02.011

White, C.M., R.R. Steeper and A.E. Lutz, 2006. The hydrogen-fueled internal combustion engine: A technical review. Int. J. Hydrogen Energy, 31: 1292-1305. DOI: 10.1016/j.ijhydene.2005.12.001

Woschni, G., 1967. A universally applicable equation for the instantaneous heat transfer coefficient in the internal combustion engine. SAE. http://www.sae.org/technical/papers/670931

Yusaf, T.F., M.Z. Yusoff, I. Hussein and S.H. Fong, 2005. A quasi one-dimensional simulation of a 4 stroke spark ignition hydrogen fuelled engine. Am. J. Applied Sci., 2: 1206-1212. DOI: 10.3844/ajassp.2005.1206.1212 